\title{
Does being an infant of gestational diabetic mother affect cerebellar size?
}

\section{Gestasyonel diyabetik anne bebeği olmak serebellum boyutlarını etkiler mi?}

\author{
Ebru YALIN IMAMOĞLU' ${ }^{1}$, Tuğba GÜRSOY ${ }^{2}$, Selim SANCAK ${ }^{3}$, Güner KARATEKIN ${ }^{4}$, Fahri OVALI ${ }^{5}$
}

\begin{abstract}
In this study, our aim was to investigate cerebellar vermis height and transverse cerebellar diameter with cranial ultrasonography in infants of gestational diabetic mothers. Forty infants of diabetic mothers (21 appropriate-for-gestational age and 19 largefor-gestational age infants) and 40 gestational-age matched healthy controls were evaluated with cranial ultrasonography within 24 hours of birth. Cerebellar vermis height and transverse cerebellar diameter were measured midsagitally from anterior fontanelle and then coronally from mastoid fontanelle. In terms of cerebellar vermis height and transverse cerebellar diameter, no statistically significant difference was found between infants of diabetic and healthy mothers. Gestational diabetes mellitus could not affect cerebellar size in neonates. In studies with larger series, evaluation of cerebellar size and morphology in infants of diabetic mothers during long-term monitorization of their neurodevelopment could be also useful.
\end{abstract}

Key words: Gestational diabetes, cerebellum, ultrasonography, neonate

\section{öz}

Bu çalışmada amacımız, yenidoğan diyabetik anne bebeklerinde kranial ultrasonografi ile serebellar vermis yüksekliği ve transvers serebellar çap parametrelerinin incelenmesidir. Kırk gestasyonel diyabetli anne bebeği (21 gebelik haftasına uygun, 19 gebelik haftasına göre büyük doğmuş bebek) ile 40 sağlıklı bebek, gebelik haftalarına göre eşleştirilerek doğumlarının ilk 24 saati içinde kranial ultrasonografi ile değerlendirildi. Serebellar vermis yüksekliği ve transvers serebellar çap sırasıyla, ön fontanel midsagital kesit ve mastoid fontanel koronal kesit kullanılarak ölçüldü. Diyabetik anne bebekleri ve kontrol grubu kıyaslandığında, serebellar vermis yüksekliği ve transvers serebellar çap ölçümleri açısından iki grup arasında anlamlı fark saptanmadı. Gestasyonel diyabet, yenidoğan bebeklerde serebellum boyutlarını etkilemeyebilir. Daha geniş serilerle yapılacak çalışmalarda, diyabetik anne bebeklerinin uzun vadede nörolojik gelişimleri değerlendirilirken serebellum boyut ve morfolojisinin de değerlendirilmesi yararlı olabilir.

Anahtar kelimeler: Gestasyonel diyabet, serebellum, ultrasonografi, yenidoğan

\section{Giriş}

Gestasyonel diyabet (GDM), ilk defa gebelikte başlayan ya da tespit edilen glukoz intoleransıdır ${ }^{1}$. Tüm gebeliklerin yaklaşık \%1-14'ünde GDM ortaya çıkmaktadır ${ }^{2}$. Gebede periferik dokulardaki belirgin insülin direnci ve pankreas $\beta$ hücrelerinden yetersiz insülin salınımının bu hastalığın ortaya çıkışında etkili olduğu öne sürülmektedir³.

Gestasyonel diyabetin bebeklerde ileri dönemde çe- şitli nörolojik sorunlara (denge/motor koordinasyon defektleri, dikkat/bellek bozuklukları, hiperaktivite, sosyal davranış bozuklukları) yol açtığı literatürde belirtilmektedir ${ }^{4-7}$.

Serebellumun, istemli hareketlerin koordinasyonu ve denge kontrolünü sağlaması yanında, bilişsel fonksiyonlar, davranış, duygudurum ve dil gelişimi gibi yüksek beyin fonksiyonlarında da önemli rolü olduğu gösterilmiştir ${ }^{8-11}$. Literatürde GDM'nin serebellum üzerine etkisini inceleyen bir hayvan çalışmasında,

Received: 01.02.2016

Accepted: 25.02 .2016

${ }^{1}$ Department of Neonatology, Ümraniye Training and Research Hospital

${ }^{2}$ Department of Neonatology, Koç University Medical Faculty

${ }^{3}$ Department of Neonatology, Abant İzzet Baysal University Medical Faculty

${ }^{4}$ Department of Neonatology, Zeynep Kamil Maternity and Children Training and Research Hospital

${ }^{5}$ Department of Neonatology, İstanbul Medeniyet University Medical Faculty

Yazışma adresi: Ebru Yalın İmamoğlu, Department of Neonatology, Umraniye Training and Research Hospital, İstanbul

e-mail: ebruli013@hotmail.com 
diyabetik sıçanların bebeklerinin postnatal 0 . günde serebellum volümlerinde artış saptanmıştır ${ }^{12}$. Hill ve ark. ${ }^{13}$ annesi diyabetik olan ve olmayan makrozomik fetüslerde transvers serebellar çap (TCD) ölçümünü yapmışlar ve TCD’nin diyabetten etkilenmediğini öne sürmüşlerdir.

Bu çalışmanın amacı, yenidoğan diyabetik anne bebeklerinde kranial ultrasonografi ile serebellar vermis yüksekliği $(\mathrm{CVH})$ ve TCD parametrelerinin incelenmesidir.

\section{GEREÇ ve YÖNTEM}

Bu kesitsel çalışmaya, 1 Ekim 2014- 30 Eylül 2015 tarihleri arasında hastanemizde doğan 40 GDM'li anne bebeği (21 gebelik haftasına uygun (AGA), 19 gebelik haftasına göre büyük doğmuş (LGA) bebek) ile 40 sağlıklı bebek (21 AGA, 19 LGA) alındı.

Doğumsal anomali, santral sinir sistemi anomalisi, kromozom anomalisi, doğumsal enfeksiyon/menenjit, metabolik hastalık, serebellar/intrakranial kanaması olan bebekler, gebelik haftasına göre küçük doğmuş (SGA) bebekler ve çoğul gebelik bebekleri çalışmaya alınmadı.

Gebelik haftası, annenin son âdet tarihinin ilk gününden itibaren hesaplanan ve ilk trimesterde erken ultrasonografi ile teyit edilen bebekler çalışmaya alındı. Gebelik haftası belli olmayan yenidoğanlar çalışmaya alınmadı.

Gestasyonel diyabet, başlangıcı ya da ilk tespiti gebelik sırasında olan, değişik derecelerde hiperglisemi ile sonuçlanan glukoz intoleransı olarak tanımland $\iota^{14}$. Gestasyonel diyabet tanısı için iki ayrı zamanda alınan açlık kan şekerinin (KŞ) $>126 \mathrm{mg} / \mathrm{dl}$ olması ya da iki ayrı zamanda rastgele alınan kanda KŞ > 200 mg/dl olması koşulu arandı 3. eğer hastaya erken gebelikte diyabet tanısı konmamışsa 24.-28. gebelik haftasında yapılan 2-saatlik $75 \mathrm{~g}$ oral glukoz tolerans testinde açlık KŞ $>92 \mathrm{mg} / \mathrm{dl}$ olması ya da 1 . saatte KŞ $>180 \mathrm{mg} / \mathrm{dl}$ ve 2 . saatte $K S ̧>150 \mathrm{mg} / \mathrm{dl}$ olması koşulu arand $\iota^{15}$.
Yenidoğan bebekler çıplak bir şekilde $\pm 5 \mathrm{~g}$ hassaslıkta elektronik tartı (Sartorius AG, Goettingen, Germany) ile tartıldı. Doğum ağırlığı 10. ve 90. persantil arasında olan bebekler ve doğum ağırlığı 90. persantilden büyük olan bebekler Türk Büyüme Eğrileri'ne göre sırasıyla AGA ve LGA bebek olarak adlandırıldı ${ }^{16}$. Tüm bebeklerin baş çevreleri (BÇ) aynı mezura ile aynı kişi tarafından ölçüldü ve kaydedildi. Her bir AGA diyabetik anne bebeği için, ardından doğan gebelik haftaları eş sağlıklı bir AGA bebek ve her bir LGA diyabetik anne bebeği için, ardından doğan gebelik haftaları eş sağııklı bir LGA bebek çalışmaya alındı.

\section{Kranial ultrasonografi}

Tüm yenidoğanlara doğumlarının ilk 24 saati içerisinde deneyimli bir yenidoğan hekimi (EYi) tarafından, multifrekans 5-12 MHz sektör prob (Philips En Visor C, Amsterdam, The Netherlands) ile kranial ultrasonografi yapıldı. Araştırmacı, bebeklerin gruplarına karşı kördü. Serebellar vermis yüksekliği ve TCD ölçümleri sırasıyla, ön fontanel midsagital kesit ve sol mastoid fontanel koronal kesit kullanılarak gerçekleştirildi ${ }^{17}$. En uygun iki boyutlu imaj, ultrasonografi ekranında donduruldu ve ardından ölçüm yapıldı. Serebellar vermis yüksekliği ve TCD ölçümleri her bir bebekte üçer defa yinelendi ve ortalama değer istatistik analiz için kullanıldı.

Araştırma Helsinki Bildirgesi doğrultusunda gerçekleştirildi. Çalışmaya alınan bebeklerin anne ve babalarından bilgilendirilmiş onam alındı ve çalışmamız yerel Etik Kurul tarafından onaylandı.

\section{İstatistik analiz}

İstatistiksel analizler IBM SPSS yazılımı (SPSS, Chicago, IL) kullanılarak yapıldı. Değişkenlerin normal dağılıma uygunluğu görsel (histogram ve olasılık grafikleri) ve analitik yöntemlerle (Kolmogorov-Smirnov/ShapiroWilk testleri) incelendi. Tanımlayıcı analizler, normal dağılan değişkenler için ortalama ve standart sapmalar ve normal dağılmayan değişkenler için ortanca ve çeyrekler arası aralık kullanılarak verildi. Normal dağıIım gösteren parametreler Student T testi ile normal 
dağılım göstermeyenler ise Mann-Whitney $U$ testi ile karşılaştırıldı. Gruplar arasında sıklıklar bakımından fark bulunup bulunmadığı ki-kare testi kullanılarak incelendi. Sonuçlar \%95'lik güven aralığında, anlamlılık $\mathrm{P}<0,05$ düzeyinde değerlendirildi.

Her bir serebellum ölçümünün doğruluğu, sınıf-içi korelasyon katsayısı (ICC) kullanılarak yapıldı. On sekizinci sınıf-içi korelasyon katsayısı 0.80 'in üzerinde olduğunda çok iyi, 0.61-0.80 arasında olduğunda iyi olarak kabul edildi.

Gözlemciler arası güvenirlik, önceki serebellum ölçümlerine kör olan kranial ultrasonografide deneyimli bir yenidoğan hekiminin (TG) ana örneklemin \%20'sinde serebellum ölçümlerini yinelemesi sonucunda değerlendirildi. Bu ölçümler ve orijinalleri ICC kullanılarak kıyaslandı. Gözlemci içi güvenirlik, önceki ölçümlere kör olan ana yazarın, ana örneklemin \%20 'sinde serebellum ölçümlerini yinelemesi sonucunda değerlendirildi. Bu ölçümler ve orijinalleri ICC kullanılarak kıyaslandı.

\section{BULGULAR}

Bu çalışmada, 40 diyabetik anne bebeği (21 AGA, 19 LGA) ve 40 sağlıklı kontrol (21 AGA, 19 LGA) bebek gebelik haftalarına göre eşleştirildi. Bebeklerin $\% 52,5^{\prime} \mathrm{i}$ AGA ve $\% 47,5$ 'i LGA idi.

Serebellar vermis yüksekliği ve TCD normal dağılım gösterdiğinden ortalamaıstandart sapma şeklinde, $B C ̧$ ise normal dağılım göstermediğinden ortanca ve çeyrekler arası aralık şeklinde belirtildi.

Diyabetik anne bebekleri ve kontrol grubunun demografik özellikleri Tablo 1'de gösterilmektedir. Her iki grubun $\mathrm{CVH}$ ve TCD ortalama değerleri ile $\mathrm{BÇ}$ ortanca değerleri Tablo 2'de verilmiştir. Diyabetik anne bebekleri ve kontrol grubu kıyaslandığında, CVH, TCD ve $B C ̧$ parametreleri açısından iki grup arasında anlamlı fark saptanmadı. Doğum ağırlığı gebelik haftasına uygun olan diyabetik anne bebekleri ile kontrol grubundaki AGA bebekler kıyaslandığında ve LGA olan diyabetik anne bebekleri ile kontrol grubundaki
LGA bebekler kıyaslandığında CVH, TCD ve BÇ parametreleri açısından gruplar arasında anlamlı fark bulunmadı (Tablo 3).

Tablo 1. Çalışma ve kontrol grubunun demografik özellikleri.

\begin{tabular}{llll}
\hline & $\begin{array}{c}\text { Diyabetik anne } \\
\text { bebekleri }\end{array}$ & Kontrol & p \\
& $38,8 \pm 1,5$ & $38,9 \pm 1,5$ & NS \\
Gebelik haftası (hf) & $3701 \pm 531$ & $3628 \pm 527$ & NS \\
Doğum ağırlığı (g) & $19 / 21$ & $15 / 25$ & NS \\
Cinsiyet (K/E) & $19 / 21$ & $15 / 25$ & NS \\
Doğum şekli (n) nsd/C/S & $30,2 \pm 5,6$ & $28,4 \pm 6$ & NS \\
Anne yaşı & & & \\
\hline
\end{tabular}

NS: anlamlı değil, nsd: normal spontan doğum, C/S: sezaryen doğum

Tablo 2. Çalışma ve kontrol grubunun serebellum ve baş çevresi ölçümleri.

\begin{tabular}{llll}
\hline & \multicolumn{1}{c}{ Diyabetik anne bebekleri } & \multicolumn{1}{c}{ Kontrol } & p \\
\hline CVH & $2,33 \pm 0,2$ & $2,25 \pm 0,2$ & NS \\
TCD & $5,33 \pm 0,3$ & $5,39 \pm 0,2$ & NS \\
BC & $35(34,3-35,6)$ & $34,8(34,1-35,4)$ & NS \\
\hline
\end{tabular}

CVH: serebellar vermis yüksekliği, TCD: transvers serebellar çap, $B C ̧:$ baş çevresi, NS: anlamlı değil.

Tablo 3. Çalışma ve kontrol grubundaki AGA ve LGA bebeklerin serebellum ve baş çevresi ölçümleri.

\begin{tabular}{lllll}
\hline & & Diyabetik anne bebekleri & \multicolumn{1}{c}{ Kontrol } & p \\
\hline AGA & & & & \\
& CVH & $2,31 \pm 0,1$ & $2,21 \pm 0,2$ & NS \\
& TCD & $5,29 \pm 0,3$ & $5,39 \pm 0,2$ & NS \\
& BÇ & $34,9(33,5-35,6)$ & $34,6(34-34,9)$ & NS \\
LGA & & & & \\
& CVH & $2,36 \pm 0,2$ & $2,3 \pm 0,2$ & NS \\
& TCD & $5,38 \pm 0,3$ & $5,39 \pm 0,2$ & NS \\
& BÇ & $35,3(34,5-35,6)$ & $35,1(34,5-36)$ & NS
\end{tabular}

AGA: doğum ağırlığı gebelik haftasına uygun, LGA: doğum ağırlığı gebelik haftasından büyük bebek, CVH: serebellar vermis yüksekliği, TCD: transvers serebellar çap, BÇ: baş çevresi, NS: anlamlı değil.

Gözlemciler arası güvenirlik CVH ve TCD parametreleri için (sırasıyla ICC: 0.84 ve ICC: 0.88 ) çok iyi olarak bulundu. Gözlemciler içi güvenirlik de CVH ve TCD parametreleri için (sırasıyla ICC: 0.92 ve ICC: 0.91) çok iyi olarak bulundu. 


\section{TARTIŞMA}

Fetüs, GDM varlığında artmış glukoz ve insülin düzeylerine maruz kalmaktadır. Glukoz, beyin için primer metabolittir ve insülinin ise büyümeyi arttırıcı etkisi bilinmektedir ${ }^{13}$. Diyabetik rhesus maymunlarla yapılmış çalışmalarda, iç organlar, yağ dokusu ve tüm vücut ağırlığında önemli ölçüde artış saptanırken, beyin ağırlığında değişiklik saptanmamıştır ${ }^{19,20}$.

Literatürde diyabetik intrauterin çevrenin, fetüsün beyin gelişimini anormal yönde etkileyebildiğini gösteren çalışmalar da bulunmaktadır ${ }^{21-23}$. Hami ve ark.'nın ${ }^{12}$ yaptığı hayvan çalışmasında, diyabetik sıçanların bebeklerinde postnatal 0 . günde total serebellum volümlerinde artış saptanmıştır. Serebellum volümünde artışa, maternal hiperglisemiye ikincil fetüste gelişen hiperglisemi, hiperinsülinizm, IGF-1 artışı ve serebellar kortekste IGF-1 reseptörlerinde artışın neden olduğu belirtilmiştir. Bu yavru sıçanlarda postnatal 14. günde ise $\mathrm{KŞ}$ 'nin düzelmesiyle insülin ve IGF-1'in azalması sonrasında serebellum volümlerinde küçülme saptanmış ve bu durum, bu bebeklerde gelişebilecek nörolojik gerilik ile ilişkilendirilmiştir. Hill ve ark.'nın ${ }^{13}$ makrozomik fetüsü olan 30 diyabetik ve 62 sağlıklı gebede yaptığı fetal ultrasonografi çalışmasında, fetal TCD ölçümlerinin makrozomiden etkilenmediği gösterilmiştir.

Bu çalışmaya ise yalnızca makrozomik (LGA) diyabetik anne bebekleri değil, aynı zamanda AGA diyabetik anne bebekleri de dâhil edilmiştir. Bildiğimiz kadarı ile bu çalışma, GDM'li anne bebeklerinde CVH ve TCD parametrelerini inceleyen literatürdeki ilk çalışmadır. Serebellar vermis yüksekliği, TCD ve BÇ ölçümleri açısından, diyabetik anne bebekleri ile gebelik haftaları eş olan sağlıklı kontrol bebekler arasında anlamlı fark bulunmamıştır. Alt grup analizinde, AGA ve LGA bebekler ayrı ayrı kendi kontrolleriyle kıyaslandığında da $C V H, T C D$ ve BÇ açısından fark bulunmamıştır.

Term/postterm bebeklerde ve özellikle kalın ve kıvırcık saçlı bebeklerde (diyabetik anne bebekleri), ön fontanelden CVH ölçümü zor olmaktadır. Posterior fossanın daha iyi görüntülenebilmesi için daha düşük frekansla (5 MHz'e kadar düşürülerek) görüntüleme yapılması daha uygundur ${ }^{24}$. Bu çalışmada da özellikle yoğun saçı olan bebeklerde daha iyi penetrasyon için, prob $5 \mathrm{MHz}$ ye ayarlandı.

Rizzo ve ark..$^{25}$ maternal diyabetin, gelişmekte olan fetal beyin hücrelerini etkileyebileceğini ve ileride bilişsel ve davranışsal sorunlara yol açabileceğini belirtmişlerdir. Bu çalışmada, diyabetik anne bebeklerinin ileri dönemdeki serebellum boyutlarını ve nörolojik gelişimlerini incelememiş olmamız bir limitasyon olarak söylenebilir.

Sonuç olarak, GDM yenidoğan bebeklerde serebellum boyutlarını etkilemeyebilir. Daha geniş serilerle yapılacak çalışmalarda, diyabetik anne bebeklerinin uzun vadede nörolojik gelişimleri değerlendirilirken serebellum boyut ve morfolojisinin de değerlendirilmesi yararlı olabilir.

\section{Çıkar Çatışması}

Çalışmada yer alan yazarlardan biri derginin editöryal kurulunda yer aldığı için çalışmanın değerlendirme aşamalarında bulunmamıştır.

\section{KAYNAKLAR}

1. Metzger BE, Coustan DR. Summary and recommendations of the Fourth International Workshop-Conference on Gestational Diabetes Mellitus. The Organizing Committee. Diabetes Care 1998;21(Suppl 2):B161-7.

2. American Diabetes Association. Gestational Diabetes. Diabetes Care 2000;23(Suppl 1):77-9.

3. Baz B, Riveline JP, Gautier JF. Endocrınology of Pregnancy: Gestational diabetes mellitus: definition, aetiological and clinical aspects. Eur J Endocrinol 2015;174:R43-51.

http://dx.doi.org/10.1530/EJE-15-0378

4. Georgieff MK. The effect of maternal diabetes during pregnancy on the neurodevelopment of offspring. Minn Med 2006;89:44-7.

5. Delascio Lopes C, Sinigaglia-Coimbra R, Mazzola J, et al. Neurofunctional evaluation of young male offspring of rat dams with diabetes induced by streptozotocin. ISRN Endocrinol 2011;2011:480656. http://dx.doi.org/10.5402/2011/480656

6. Nelson CA, Wewerka S, Thomas KM, et al. Neurocognitive sequelae of infants of diabetic mothers. Behav Neurosci 2000;114:950-6. http://dx.doi.org/10.1037/0735-7044.114.5.950

7. Ornoy A. Growth and neurodevelopmental outcome of children born to mothers with pregestational and gestational dia- 
betes. Pediatr Endocrinol Rev 2005;3:104-13.

8. Brooks VB. Comment: on functions of the "cerebellar circuit" in movement control. Can J Physiol Pharmacol 1981;59:776-8.

http://dx.doi.org/10.1139/y81-113

9. Beaton A, Mariën P. Language, cognition and the cerebellum: grappling with an enigma. Cortex 2010;46:811-20. http://dx.doi.org/10.1016/j.cortex.2010.02.005

10. Schmahmann JD, Caplan D. Cognition, emotion and the cerebellum. Brain 2006;129:290-2. http://dx.doi.org/10.1093/brain/awh729

11. Tavano A, Grasso R, Gagliardi C, et al. Disorders of cognitive and affective development in cerebellar malformations. Brain 2007;130:2646-60. http://dx.doi.org/10.1093/brain/awm201

12. Hami J, Vafaei-Nezhad S, Haghir D, Haghir H. Insulin-Like growth factor-1 receptor is differentially distributed in developing cerebellar cortex of rats born to diabetic mothers. $J$ Mol Neurosci 2016;58:221-32. http://dx.doi.org/10.1007/s12031-015-0661-z

13. Hill LM, Guzick D, Fries J, et al. The transverse cerebellar diameter in estimating gestational age in the large for gestational age fetus. Obstet Gynecol 1990;75:981-5.

14. Metzger BE, Coustan DR. Summary and recommendations of the Fourth International Workshop-Conference on Gestational Diabetes Mellitus. The Organizing Committee. Diabetes Care 1998;21(Suppl 2):B161-7.

15. Poulakos P, Mintziori G, Tsirou E, et al. Comments on gestational diabetes mellitus: from pathophysiology to clinical practice. Hormones (Athens) 2015;14:335-44. http://dx.doi.org/10.14310/horm.2002.1570

16. Ovali F. Intrauterine growth curves for Turkish infants born between 25 and 42 weeks of gestation. J Trop Pediatr 2003;49:381-3.

http://dx.doi.org/10.1093/tropej/49.6.381
17. Imamoglu EY, Gursoy T, Ovali F, et al. Nomograms of cerebellar vermis height and transverse cerebellar diameter in appropriate-for-gestational-age neonates. Early Hum Dev 2013;89:919-23.

http://dx.doi.org/10.1016/j.earlhumdev.2013.10.001

18. Brennan P, Silman A. Statistical methods for assessing observer variability in clinical measures. BMJ 1992;304:1491-4. http://dx.doi.org/10.1136/bmj.304.6840.1491

19. Cheek DB, Hill DE. Changes in somatic growth after ablation of maternal or fetal pancreatic beta cells. In: Fetal and postnatal cellular growth. Cheek DB, ed. Wiley, New York, 1975.

20. Susa JB, McCormick KL, Widness JA, et al. Chronic hyperinsulinemia in the fetal rhesus monkey: effects on fetal growth and composition. Diabetes 1979;28:1058-63. http://dx.doi.org/10.2337/diab.28.12.1058

21. Allen G, Buxton RB, Wong EC, Courchesne E. Attentional activation of the cerebellum independent of motor involvement. Science 1997;275:1940-3. http://dx.doi.org/10.1126/science.275.5308.1940

22. Simán CM, Eriksson UJ. Vitamin C supplementation of the maternal diet reduces the rate of malformation in the offspring of diabetic rats. Diabetologia 1997;40:1416-24. http://dx.doi.org/10.1007/s001250050844

23. Simán CM, Eriksson UJ. Vitamin E decreases the occurrence of malformations in the offspring of diabetic rats. Diabetes 1997;46:1054-61. http://dx.doi.org/10.2337/diab.46.6.1054

24. van Wezel-Meijler Gerda. Cranial ultrasonography: technical aspects. In:Neonatal cranial ultrasonography, guidelines for the procedure and atlas of normal anatomy. Heilmann $U$, editor. Springer Verlag, Berlin Heidelberg; 2007: p.9-15.

25. Rizzo T, Freinkel N, Metzger BE, et al. Correlations between antepartum maternal metabolism and newborn behavior. Am J Obstet Gynecol 1990;163:1458-64. http://dx.doi.org/10.1016/0002-9378(90)90606-8 